\title{
Evaluation of antioxidant activity of Mimosa pudica L. extracts
}

\author{
Ujjwal Kumar Mondol and W Islam* \\ Institute of Biological Sciences, University of Rajshahi, Bangladesh. \\ International Journal of Biological and Pharmaceutical Sciences Archive, 2022, 03(01), 015-020
}

Publication history: Received on 21 November 2021; revised on 14 January 2022; accepted on 16 January 2022

Article DOI: https://doi.org/10.53771/ijbpsa.2022.3.1.0071

\begin{abstract}
Antioxidant activity of petroleum ether, chloroform, ethyl acetate and methanol extracts of leaf, stem and root of Mimosa pudica L. was observed through DPPH (2,2-diphenyl-1-picrylhydrazyl) free radical scavenging assay. Five concentrations $(12.5,25.0,50.0,100.0$ and $200.0 \mu \mathrm{g} / \mathrm{ml})$ were taken for each extract as well as the standard and the absorbances were measured at $517 \mathrm{~nm}$ using a spectrophotometer against methanol blank. The activity was increased by the increment of concentrations of the extracts. In case of leaf, the highest scavenging percentage was found in chloroform extract $(86.40 \%)$ at $200.0 \mu \mathrm{g} / \mathrm{ml}$ concentration. But for stem and root, the highest scavenging percentages were found in ethyl acetate extracts $(73.72 \%$ and $83.79 \%$ respectively) at same concentration. The ethyl acetate extracts showed the highest activity among all the extracts where the $\mathrm{IC}_{50}$ values were $65.152 \mu \mathrm{g} / \mathrm{ml}, 76.036 \mu \mathrm{g} / \mathrm{ml}$ and $65.000 \mu \mathrm{g} / \mathrm{ml}$ and the lowest was found in petroleum ether extracts where the $\mathrm{IC}_{50}$ values were $130.129 \mu \mathrm{g} / \mathrm{ml}$, $147.891 \mu \mathrm{g} / \mathrm{ml}$ and $186.449 \mu \mathrm{g} / \mathrm{ml}$ for leaf, stem and root respectively and that was for ascorbic acid (standard) was $18.012 \mu \mathrm{g} / \mathrm{ml}$.
\end{abstract}

Keywords: Antioxidant; Phytochemicals; Reactive oxygen species; DPPH (2, 2-diphenyl-1-picrylhydrazyl); Diamagnetic molecule; Spectrophotometer

\section{Introduction}

Plants contain bioactive constituents that are used as traditional medicines as well as modern medicine and these natural compounds are used for phytotherapy and pharmaceutical drugs (Sahu et al. 2015). A large number of factors such as xenobiotics, radiation or exposure to heavy metals are responsible for inducing oxidative stress and enhancing the production of free radicals (Shinde et al. 2016). Antioxidants derived from natural sources have less adverse effects and very much promising for its better efficacy. The damage of cells are prevented by the antioxidants significantly by scavenging the free radicals and reactive oxygen species developed in different diseases as hepatic failure, diabetes mellitus, renal failure, atherosclerosis, inflammation, cancer, etc. (Bulkley 1983, Halliwell and Gutteridge 1993, Niki 1995 and Frei 1999). Herbal plants, vegetables and fruits possess the antioxidants such as Vitamin C, Vitamin E, flavonoids, polyphenol, phenolics, tannins and proanthocyanidins. So the consumption of antioxidant rich diet may prevent the oxidative stress induced degenerative diseases (Habib and Ibrahim 2011, Hendra et al. 2011 and Gulcin 2012). The present study serves as a basis for further research to isolate the bioactive compounds for discovery of new herbal drugs.

\section{Material and methods}

DPPH (2,2-diphenyl-1-picrylhydrazyl) was used to evaluate the free radical scavenging activity of petroleum ether, chloroform, ethyl acetate and methanol extracts of leaf, stem and root of Mimosa pudica $\mathrm{L}$.

\footnotetext{
* Corresponding author: W Islam

Institute of Biological Sciences, University of Rajshahi, Bangladesh.

Copyright $(2022$ Author(s) retain the copyright of this article. This article is published under the terms of the Creative Commons Attribution Liscense 4.0.
} 


\subsection{DPPH free radical scavenging principle}

DPPH radical is widely used to evaluate the free radical scavenging capacity of antioxidants (Choi et al. 2000). This free radical is reduced to corresponding hydrazine when it reacts with hydrogen donors. It can make stable the free radicals in aqueous or methanol solution.

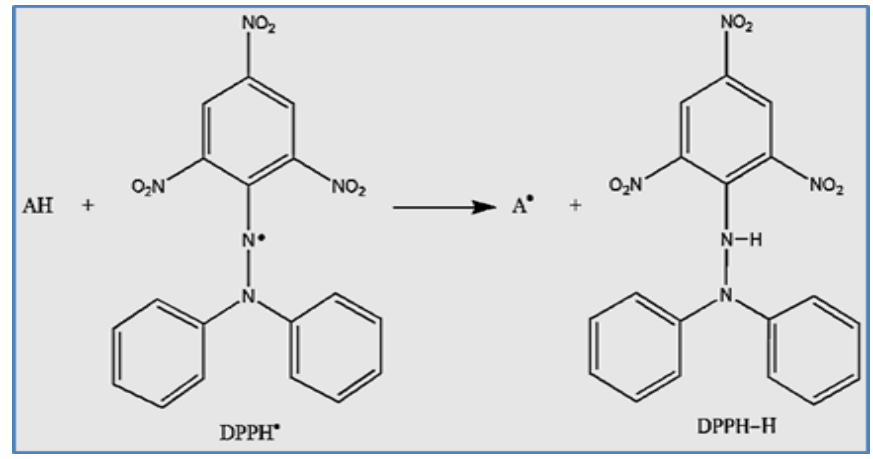

Figure 1 Principle of antioxidant molecule

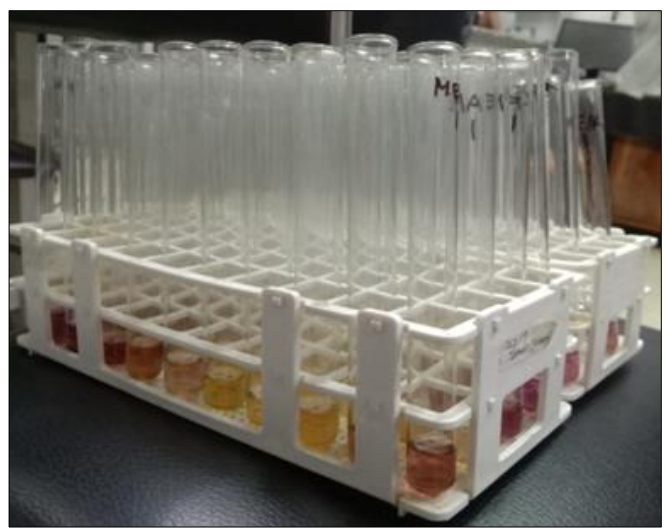

Figure 2 Antioxidant activity of $M$. pudica

By following this method, it is possible to determine the antiradical power of an antioxidant by measuring the decrease in absorbance of DPPH at $517 \mathrm{~nm}$. Resulting from a color change from purple to yellow, the absorbance decreased when DPPH is scavenged by an antioxidant through donation of hydrogen to form a stable DPPH molecule. In the radical form, this molecule has an absorbance at $517 \mathrm{~nm}$ which disappears after acceptance of an electron or hydrogen radical from an antioxidant compound to become a stable diamagnetic molecule (Figure 1).

\subsection{Experimental procedure}

DPPH radical scavenging activity of the extracts was measured by the method developed by Manzorro et al. (1998). Stock solution was made by mixing $1 \mathrm{mg}$ extract in $1 \mathrm{ml}$ methanol. $3.94 \mathrm{mg}$ DPPH was added in $100 \mathrm{ml}$ methanol and vortex well. Extracts and standard of each concentration $(12.5,25.0,50.0,100.0$ and 200.0 $\mu \mathrm{g} / \mathrm{ml})$ were mixed with $1.5 \mathrm{ml}$ of DPPH solution $(0.1 \mathrm{mM})$. The reaction was carried out at room temperature in a dark place for $30 \mathrm{minutes}$ and the absorbance was measured at $517 \mathrm{~nm}$. IC 50 values (concentration of samples required to scavenge $50 \%$ of free radicals) were calculated from the regression equation, developed by plotting concentration of samples versus percentage inhibition of free radicals (Figure 3). Ascorbic acid was used as positive control.

\subsection{Preparation for antioxidant activity test}

At first, all equipment's were washed and sterilized carefully. Different concentrations i.e. 12.5, 25.0, 50.0, 100.0 and $200.0 \mu \mathrm{g} / \mathrm{ml}$ of the extracts and a standard were taken in test tubes. $1.5 \mathrm{ml}$ of methanol solution of DPPH was added into each of the test tubes. The test tubes were then incubated at room temperature for 30 minutes in dark place to complete the reaction. Then the absorbances of solutions were measured at $517 \mathrm{~nm}$ using a spectrophotometer against blank. Methanol was used as a blank. Control sample was prepared containing the same amount of methanol and DPPH without plant extracts and it was incubated under the same conditions as rest of the sample solutions (Figure 2). 


\subsection{Reading and analysis of data for antioxidant activity test}

The percentage (\%) inhibition activity of DPPH was calculated from the following equation:

$$
\% I=\left\{\left(A_{0}-A_{1}\right) / A_{0}\right\} X 100
$$

Where, $\mathrm{A}_{0}$ is absorbance of the control and $\mathrm{A}_{1}$ is the absorbance of the extract/standard.

The percent inhibitions were plotted against concentration and $\mathrm{IC}_{50}$ was calculated from graph.

\section{Results and discussion}

The free radical scavenging capacity of different solvent extracts of leaf, stem and root of $M$. pudica were estimated using the stable DPPH (2-2-Diphenyl-1-picrylhydrazyl) radical with absorbance at $517 \mathrm{~nm}$. Ethyl acetate crude extracts showed well antioxidant activity in comparison to ascorbic acid as standard. Different solvent extracts of leaf, stem and root showed moderate to high antioxidant properties. Absorbance at $517 \mathrm{~nm}$ was gradually decreased with higher concentrations of the samples in respect to control. It was quantitatively measured from the change in absorbance and percent of scavenging activity was calculated. The activity was increased by increment of concentration of the extracts. All the extracts of leaf, stem and root possessed significant DPPH free radical scavenging activity.

Table 1 DPPH free radical scavenging activity of different extracts of leaf of $M$. pudica and Ascorbic acid as standard at different concentrations

\begin{tabular}{|c|c|c|c|c|c|}
\hline \multirow{2}{*}{$\begin{array}{c}\text { Concentrations } \\
(\boldsymbol{\mu g} / \mathbf{m l})\end{array}$} & Petroleum ether & Chloroform & Ethyl acetate & Methanol & Ascorbic acid \\
\cline { 2 - 6 } & 7.45 & 9.67 & 41.29 & 26.69 & 45.41 \\
\hline 12.5 & 16.92 & 22.66 & 50.45 & 38.97 & 72.47 \\
\hline 50.0 & 32.23 & 36.96 & 63.75 & 53.17 & 88.96 \\
\hline 100.0 & 48.74 & 67.88 & 69.39 & 66.97 & 94.25 \\
\hline 200.0 & 66.67 & 86.40 & 74.62 & 76.03 & 96.11 \\
\hline
\end{tabular}

Table 2 DPPH free radical scavenging activity of different extracts of stem of $M$. pudica and Ascorbic acid as standard at different concentrations

\begin{tabular}{|c|c|c|c|c|c|}
\hline \multirow{2}{*}{$\begin{array}{c}\text { Concentrations } \\
(\boldsymbol{\mu g} / \mathbf{m l})\end{array}$} & Petroleum ether & Chloroform & Ethyl acetate & Methanol & Ascorbic acid \\
\cline { 2 - 6 } & 3.02 & 16.82 & 36.15 & 10.07 & 45.41 \\
\hline 25.5 & 9.06 & 27.09 & 47.73 & 16.31 & 72.47 \\
\hline 50.0 & 21.95 & 37.76 & 56.29 & 33.53 & 88.96 \\
\hline 100.0 & 43.00 & 63.24 & 67.27 & 50.55 & 94.25 \\
\hline 200.0 & 62.24 & 72.61 & 73.72 & 62.24 & 96.11 \\
\hline
\end{tabular}

Among the different extracts of leaf of $M$. pudica, the highest scavenging activity was found in chloroform extract at $200.0 \mu \mathrm{g} / \mathrm{ml}$ concentration which was slightly lower than that of standard ascorbic acid; while petroleum ether, ethyl acetate and methanol extracts showed moderate scavenging activity (Table 1). Rajendran et al. (2010) denoted that the chloroform extract obtained from $M$. pudica have significant antioxidant activity and the antioxidant potential might be due to the phytoconstituents like alkaloids, glycosides, flavonoids, steroids and phenolic compounds. The reducing power of M. pudica leaf extracts was very potent and the activity increased with quantity of sample. The chloroform extract not only scavenged off free radicals but also inhibited the generation of free radicals. The present study showed more or less similar results. Das et al. (2014) depicted that the IC 50 values of methanolic leaf extract of $M$. pudica through DPPH free radical scavenging assay was $126.71 \mu \mathrm{g} / \mathrm{ml}$ and that of for ascorbic acid was $20.13 \mu \mathrm{g} / \mathrm{ml}$. They mentioned that the DPPH reading was very close to ascorbic acid as the leaf extract of the plant was in crude form. These findings were nearly close to the present result where the IC 50 values of DPPH free radical scavenging activity of methanolic leaf 
extract and ascorbic acid were $84.700 \mu \mathrm{g} / \mathrm{ml}$ and $18.012 \mu \mathrm{g} / \mathrm{ml}$ respectively. But Arokiyaraj et al. (2012) showed somewhat different result; where they mentioned that the methanolic extract of leaf of $M$. pudica had a significant free radical scavenging activity generated by DPPH where the IC50 was $9.0 \mathrm{mg} / \mathrm{ml}$. Almalki (2016) denoted that the hexane extract of leaves of M. pudica showed a significant scavenging effect on DPPH free radical (IC 50 20.83mM) and vitamin $\mathrm{C}(22.6 \mathrm{mM})$ and the leaves of $M$. pudica were good antioxidant agent. But in the present study the petroleum ether leaf extract showed moderate DPPH scavenging effect where the IC 50 was $130.129 \mu \mathrm{g} / \mathrm{ml}$.

Table 3 DPPH free radical scavenging activity of different extracts of root of M. pudica and Ascorbic acid as standard at different concentrations

\begin{tabular}{|c|c|c|c|c|c|}
\hline \multirow{2}{*}{$\begin{array}{c}\text { Concentrations } \\
(\boldsymbol{\mu g} / \mathbf{m l})\end{array}$} & \multicolumn{5}{|c|}{ Scavenging (\%) } \\
\cline { 2 - 6 } & Petroleum ether & Chloroform & Ethyl acetate & Methanol & Ascorbic acid \\
\hline 12.5 & 10.57 & 9.06 & 27.09 & 35.95 & 45.41 \\
\hline 25.0 & 15.11 & 17.02 & 48.74 & 43.50 & 72.47 \\
\hline 50.0 & 24.17 & 26.38 & 65.56 & 50.76 & 88.96 \\
\hline 100.0 & 34.84 & 38.17 & 74.22 & 64.35 & 94.25 \\
\hline 200.0 & 49.35 & 57.40 & 83.79 & 78.95 & 96.11 \\
\hline
\end{tabular}

Table 4 IC 50 values of different extracts of leaf, stem and root of $M$. pudica and Ascorbic acid as standard

\begin{tabular}{|l|c|c|c|c|c|}
\hline \multirow{2}{*}{ Extracts } & \multicolumn{5}{|c|}{ IC 5 values $(\boldsymbol{\mu g} / \mathbf{m l})$} \\
\cline { 2 - 5 } & Petroleum ether & Chloroform & Ethyl acetate & Methanol & Ascorbic acid \\
\hline Leaf & 130.129 & 94.293 & 65.152 & 84.700 & \\
\cline { 1 - 5 } Stem & 147.891 & 105.414 & 76.036 & 135.030 & \multirow{2}{*}{18.012} \\
\hline Root & 186.449 & 159.276 & 65.000 & 79.213 & \\
\hline
\end{tabular}

Among the different extracts of stem, the highest scavenging activity was found in ethyl acetate extract at all concentrations and all the extracts showed moderate scavenging activity in comparison to ascorbic acid (Table 2). DPPH free radical scavenging assay was carried out by Tunna et al. (2015) to determine the free radical scavenging potential of extracts of aerial parts of $M$. pudica. The initial ethanol extract (mother extract) and subsequent subfractions (hexane, ethyl acetate, acetone and methanol) were evaluated for their free radical scavenging activity and found that the methanol extract (initial or mother extract) possessed the lowest $\mathrm{IC}_{50}$ value $(7.18 \pm 0.0005)$. The hexane fraction showed a higher $\mathrm{IC}_{50}$ value but a weaker antioxidant activity of $92.302 \pm 0.0077$. In the present study, the petroleum ether extracts showed more or less similar results as hexane fraction where the IC $_{50}$ values were $130.129 \mu \mathrm{g} / \mathrm{ml}$ and $147.891 \mu \mathrm{g} / \mathrm{ml}$ for leaf and stem respectively. The methanol crude extract of aerial part of $M$. pudica showed moderate antioxidant activity compared to ascorbic acid as standard where the $\mathrm{IC}_{50}$ values were $296.62 \mu \mathrm{g} / \mathrm{ml}$ and $131.29 \mu \mathrm{g} / \mathrm{ml}$ for methanol extract and ascorbic acid respectively against DPPH free radical scavenging assay (Chowdhury et al. 2008). The present study, also showed moderate antioxidant activity for methanol crude extracts of leaf and stem i.e. the aerial parts of the plant where the $\mathrm{IC}_{50}$ values were $84.700 \mu \mathrm{g} / \mathrm{ml}$ and $135.030 \mu \mathrm{g} / \mathrm{ml}$ for methanol extracts of leaf and stem respectively.

Among the different extracts of root, the highest scavenging activity was found in ethyl acetate extract at all concentrations which was slightly lower than that of standard ascorbic acid. On the other hand, petroleum ether and chloroform extracts showed lower scavenging activity and methanol extract showed moderate scavenging activity (Table 3).

The ethyl acetate extracts showed the highest antioxidant activity among all the extracts where the IC 50 values were $65.152 \mu \mathrm{g} / \mathrm{ml}, 76.036 \mu \mathrm{g} / \mathrm{ml}$ and $65.000 \mu \mathrm{g} / \mathrm{ml}$ and the petroleum ether extracts showed the lowest activity where the $\mathrm{IC}_{50}$ values were $130.129 \mu \mathrm{g} / \mathrm{ml}, 147.891 \mu \mathrm{g} / \mathrm{ml}$ and $186.449 \mu \mathrm{g} / \mathrm{ml}$ for leaf, stem and root respectively. The IC 50 value of the standard ascorbic acid was found $18.012 \mu \mathrm{g} / \mathrm{ml}$ (Table 4 ). 

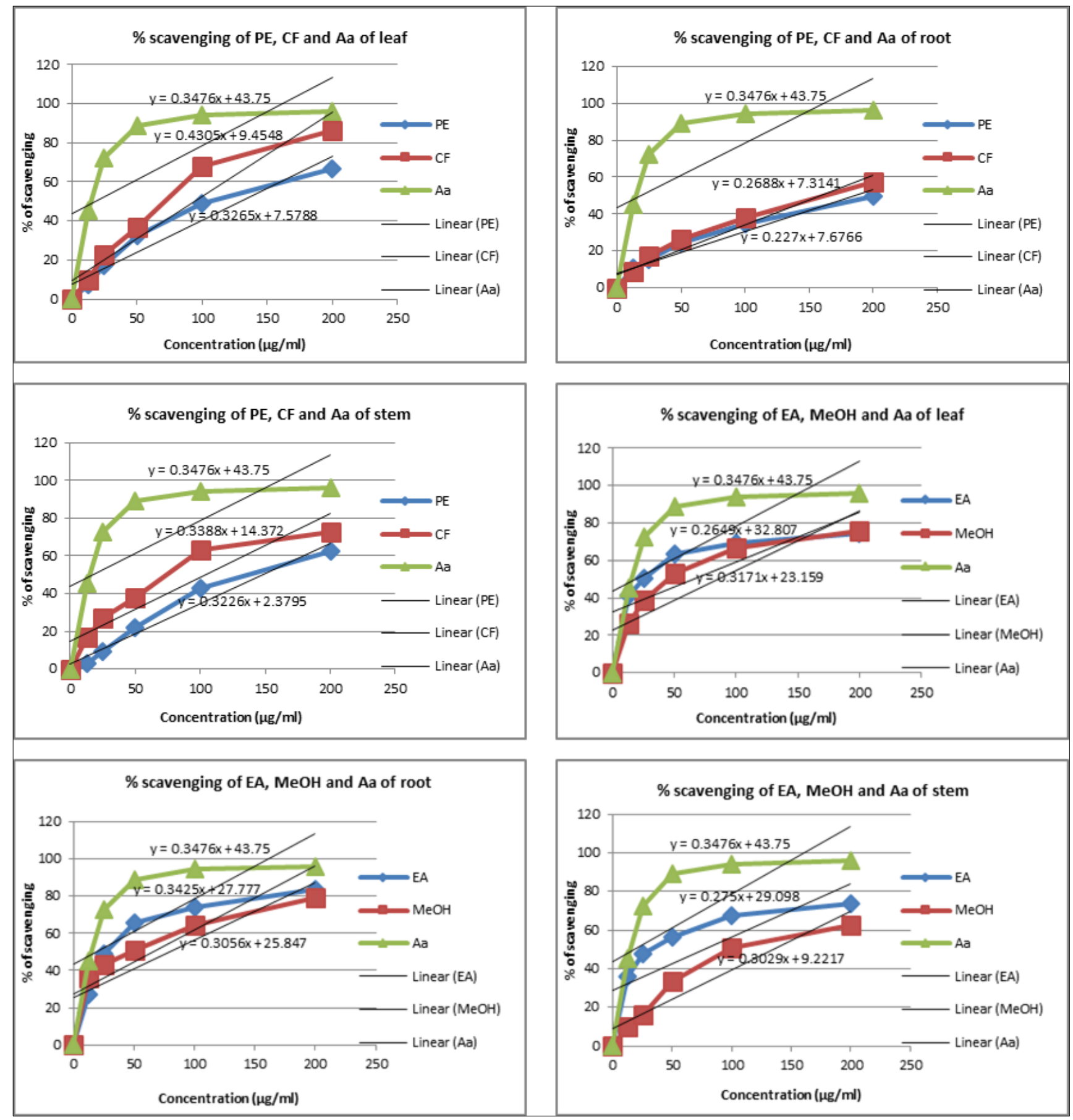

Figure 3 Regression lines between concentration and \% of scavenging of different solvent extracts of M. pudica and the standard for DPPH free radical scavenging activity

\section{Conclusion}

In the present study the antioxidant activity of different solvent extracts of $M$. pudica was evaluated at different concentrations. Among the extracts, the highest activity or the lowest $\mathrm{IC}_{50}$ value was observed in ethyl acetate extracts and the lowest activity or the highest IC 50 value was observed in petroleum ether extracts of leaf, stem and root. But in respect of scavenging activity, the highest percentage was found in chloroform extract of leaf $(86.40 \%)$ at $200 \mu \mathrm{g} / \mathrm{ml}$ concentration. The IC 50 values of DPPH radical scavenging activity could be arranged as ethyl acetate $>$ methanol $>$ chloroform $>$ petroleum ether for leaf and root, and as ethyl acetate $>$ chloroform $>$ methanol $>$ petroleum ether for stem. 


\section{Compliance with ethical standards}

\section{Acknowledgments}

I thank my supervisor Professor Dr Md Wahedul Islam, Entomology and Insect Biotechnology Laboratory, Institute of Biological Sciences, University of Rajshahi, Bangladesh for his support throughout the research. I owe thanks to University Grants Commission for financial support and the Director, Institute of Biological Sciences, University of Rajshahi for providing necessary laboratory facilities for the completion of this study.

\section{Disclosure of conflict of interest}

The authors declare that there is no conflict of interest exist.

\section{References}

[1] Almalki MA. In-vitro antioxidant properties of leaf extract of Mimosa pudica Linn. Ind. J. Sci. Tech. 2016; 9: 1-6.

[2] Arokiyaraj S, Sripriya N, Bhagya R, Radhika B, Prameela L, Udayaprakash NK. Phytochemical screening, antibacterial and free radical scavenging effects of Artemisia nilagirica, Mimosa pudica and Clerodendrum siphonanthus - An in-vitro study. Asian. Pac. J. Trop. Biomed. 2012; 2: 601-604.

[3] Bulkley GB. The role of oxygen free radicals in disease processes. Surgery. 1983; 94: 407-411.

[4] Choi H-S, Song HS, Ukeda H, Sawamura M. Radical-scavenging activities of citrus essential oils and their components: detection using 1,1-diphenyl-2-picrylhydrazyl. J. Agri. Food Chem. 2000; 48: 4156-4161.

[5] Chowdhury SA, Islam J, Rahaman M, Rahman M, Rumzhum NN, Sultana R. Cytotoxic, antimicrobial and antioxidant activities of the different plant parts of Mimosa pudica. S. J. Pharm. Sci. 2008; 1: 80-84.

[6] Das K, Yasin M, Mahbub NU, Islam MS, Mahbuba N. Evaluation of antioxidant and cytotoxic activity of methanolic extract of Mimosa pudica leaves. The Pharma Inova. J. 2014; 3: 33-36.

[7] Frei B. On the role of vitamin C and antioxidants in atherogenesis and vascular dysfunction. Proc. Soc. Exp. Bio.l Med. 1999; 222: 196-204.

[8] Gulcin I. Antioxidant activity of food constituents: An overview. Arch. Toxicol. 2012; 86: 345-391.

[9] Habib HM, Ibrahim WH. Effect of date seeds on oxidative damage and antioxidant status in vivo. J. Sci. Food Agri. 2011; 91: 1674-1679.

[10] Halliwell B, Gutteridge JMC. Free Radical in Biology and Medicine, Ed 2, London: Clarendon Oxford Press. 1993.

[11] Hendra R, Ahmad S, Sukari A, Shukor MY, Oskoueian E. "Flavonoid analyses and antimicrobial activity of various parts of Phaleria macrocarpa (Scheff.) Boerl fruit," Int. J. Molecul. Sci. 2011; 12: 3422-3431.

[12] Manzorro L, Anese M, Nicoli MC. Antioxidant properties of tea extracts as affected by processing. Lebens-mittel Wissenschaft Und-Technologie. 1998; 31: 694-698.

[13] Niki E. Antioxidants, free radicals and biological defense. In: Niki E, Shimasaki H and Mino M (Eds.). Jap. Sci. Soc. Press, Tokyo. 1995; 3.

[14] Rajendran R, Hemachander R, Ezhilarasan T, Keerthana C, Saroja DL, Saichand KV, Abdullah MG. Phytochemical analysis and in-vitro antioxidant activity of Mimosa pudica Lin., leaves. Res. J. Pharm. Tech. 2010; 3: 551-5.

[15] Sahu PR, Khalkho AS, Kumari S, Alam S. Studies on ethnomedicinal uses and formulation of herbal drugs from medicinal plants of Ranchi district-a survey. Am. J. Ethnomed. 2015; 2: 284-96.

[16] Shinde DB, Koratkar SS, Sharma NE, Shitole AA. Antioxidant activity and antiproliferative action of methanolic extract of liquorice (Glycyrrhiza glabra) in HepG2 cell line. Int. J. Pharm. Sci. 2016; 8: 293-298.

[17] Tunna TS, Zaidul ISM, Ahmed QU, Ghafoor K, Al-Juhaimi FY, Uddin MS, Hasan M, Ferdous S. Analyses and profiling of extract and fractions of neglected weed Mimosa pudica Linn. Traditionally used in Southeast Asia to treat diabetes. South Afri. J. Bot. 2016; 99: 144-152. 